\title{
Crosstalk between Beclin-1-dependent autophagy and caspase-dependent apoptosis induced by tanshinone IIA in human osteosarcoma MG-63 cells
}

\author{
$\mathrm{KUN} \mathrm{MA}^{1 *}, \mathrm{CHUAN}^{*} \mathrm{HANG}^{1 *}$, MAN-YU HUANG $^{1}, \mathrm{YAN}-X I N G ~ G U O^{1}$ and GUO-QIANG HU ${ }^{2}$ \\ ${ }^{1}$ Luoyang Orthopaedic-Traumatological Hospital and Henan Orthopaedic Hospital, Luoyang, Henan 471002; \\ ${ }^{2}$ College of Pharmacy, Henan University, Kaifeng, Henan 475000, P.R. China
}

Received March 27, 2016; Accepted May 5, 2016

DOI: $10.3892 /$ or.2016.5003

\begin{abstract}
The aim of the present study was to ascertain whether or not autophagy is induced by tanshinone IIA (TanIIA), and to explore the crosstalk between autophagy and apoptosis in regards to the antitumor effects of TanIIA on MG-63 cells and the potential mechanism. MG-63 cells were cultured in vitro with various concentrations of TanIIA $(0,2.5,5,10$ and $20 \mathrm{mg} / \mathrm{l})$ for $0,24,48$ and $72 \mathrm{~h}$, respectively. 3-(4,5-Dimethylthiazol-2-yl)-2,5-diphenyltetrazolium bromide MTT assay was used to evaluate the inhibition of the proliferation of osteosarcoma MG-63 cells by TanIIA or in the presence/absence of chloroquine (CQ). Autophagic vacuoles and characteristic autophagosomes were observed by transmission electron microscopy (TEM). TanIIA-induced autophagy in MG-63 cells was confirmed by GFP-LC3 punctate fluorescence. The expression levels of apoptosis-related proteins caspase-3, caspase-8, caspase-9 and cleaved-PARP and autophagy-related proteins LC3II/LC3I and Beclin-1 were detected by western blotting. FITC-Annexin V/propidium iodide (PI) staining, flow cytometry and Hoechst 33258 staining were used to analyze the apoptotic rate. Fluorescence intensity of reactive oxygen species (ROS) was examined under a fluorescence microscope using an analysis software system. Cell proliferation was obviously inhibited by TanIIA in a dose- and time-dependent manner. Generation of autophagy was triggered by TanIIA (0-20 mg/l) treatment, and in a Beclin-1-dependent manner. Compared with the control group, the apoptosis ratio following treatment with $2.5 \mathrm{mg} / \mathrm{l}$ TanIIA failed to achieve statistical significance. Expression of
\end{abstract}

Correspondence to: Dr Yan-Xing Guo, Luoyang OrthopaedicTraumatological Hospital and Henan Orthopaedic Hospital, 82 QiMing Road, Luoyang, Henan 471002, P.R. China

E-mail: lyzg090915@163.com

*Contributed equally

Key words: osteosarcoma, tanshinone IIA, apoptosis, autophagy, ROS caspase-3, -8 and -9, and cleaved-PARP in the other groups was gradually enhanced in dose-dependent manner. Our analysis also suggested that the influence of autophagy on TanIIA cytotoxicity had a phase effect; with low-dose drugs and shorter treatment periods, autophagy functioned as a damage repair mechanism. In conrast, when the cells were treated with higher doses of TanIIA for longer treatment periods, autophagic cell death contributed to apoptosis. Furthermore, generation of ROS occurred in a dose-dependent manner and pretreatment with NAC, a selective ROS scavenger, blocked the coexistence of Beclin-1 autophagy and caspase-dependent apoptosis. In conclusion, our findings provide strong evidence that TanIIA may be a potential therapeutic drug against osteosarcoma. Moreover, its cytotoxity can be enhanced with ROS agonists.

\section{Introduction}

Osteosarcoma is a primary malignant bone tumor found in children and adolescents (1). Osteosarcoma is characterized by a high metastatic spread tendency, poor prognosis and low patient survival rate. The current treatments for osteosarcoma include surgery, radiation, chemotherapy or a combination of radiotherapy and chemotherapy. However, the 5-year survival of patients remains 5-20\% (2).

Programmed cell death (PCD) is genetically regulated cell death, involving a series of activation, expression and regulation of genes, which include the following forms: apoptosis, autophagy and necrosis (3). In recent years, autophagy has received wide attention as having an important role in tumorigenesis and tumor therapy. Autophagy, type II programmed cell death, which is activated by numerous stresses such as nutrient starvation, hypoxia (4), intracellular reactive oxygen species (ROS) levels, bacteria and virus infection or chemical drugs and oxidative stress, is an evolutionally conserved lysosomal activity to degrade and recycle long-lived proteins and damaged cytoplasmic organelles in order to maintain cell homeostasis (5). Moderate autophagy acts as self-protection against cytotoxicity. However, consequent excessive autophagy may lead to 'autophagic cell death (type II PCD)' (6). The relationship between autophagy and apoptosis is complex and may often appear contradictory, but this relationship is critical to the overall fate of the cell (7). 
ROS are recognized as oxygen-containing, reactive and short-lived molecules, that act as secondary messengers in various signal transductions (8). ROS include the superoxide anion $\left(\mathrm{O}_{2}^{--}\right)$, the hydroxyl radical (HO) and hydrogen peroxide $\left(\mathrm{H}_{2} \mathrm{O}_{2}\right)$. When at physiological levels, ROS have been recognized to modulate cell signaling molecules. However, aberrantly high ROS expression is intimately associated with disease and is commonly observed in cancer (9). Upregulation of intracellular ROS levels may then increase mitochondrial dysfunction and consequent oxidization of proteins, lipids and DNA, redox imbalance and oxidative stress. Various anticancer treatments have been shown to promote ROS-induced autophagy which contributes to the development of cell drug resistance and to the induction of apoptosis or both, and several models between ROS and autophagy in cancer treatment have been proposed (10).

Tanshinone IIA (TanIIA) is one of the major lipophilic components isolated from the root of Salvia miltiorrhiza, a widely used herbal medicine (11). It is traditionally used in the clinic to expand coronary blood vessels, for anti-lipid peroxidation and cerebrovascular diseases $(12,13)$. TanIIA has been extensively studied for its effects on a variety of cancer cell types, including, but not limited to breast (14), lung (15), prostate (16) and bladder cancer (17), through a variety of detailed mechanisms including antiangiogenic effects via inhibition of HIF-1 $\alpha$, repression of IL-6/Stat3 signaling, modulation of apoptotic regulators, regulation of epigenetic modifications and miRs, and inhibition of glucose metabolism (18-22). In recent years, research found that TanIIA induces autophagy in cancer cells (23-25), and plays a pro-survival or pro-death role in cancer therapy.

Moreover, Zhang et al (26) confirmed that TanIIA induced apoptosis in osteosarcoma MG-63 cells, but there are no studies on whether TanIIA triggers autophagy in MG-63 cells and the underlying mechanism. Our experiments aimed to ascertain the following: firstly, whether TanIIA induces autophagy in MG-63 cells; and secondly, to define the relationship between ROS, autophagy and apoptosis induced by TanIIA in human MG-63 cells.

\section{Materials and methods}

Reagents. TanIIA was purchased from the National Institute for the Control of Pharmaceutical and Biological Products (Beijing, China), and was then diluted with Dulbecco's modified Eagle's medium (DMEM) (Gibco, Grand Island, NY, USA) to the desired working concentration before each experiment. Fetal bovine serum (FBS) was purchased from Hangzhou Sijiqing Biological Engineering Material Co., Ltd. (Hangzhou, Zhejiang, China). Chloroquine (CQ), and 3-(4,5-dimethylthiazol2-yl)-2,5-diphenyltetrazolium bromide (MTT) and $N$-acetyl cysteine were purchased from Sigma (St. Louis, MO, USA). Hoechst 33258 was purchased from Promega (Madison, WI, USA). Lipofectamine 2000 transfection reagent was obtained from Invitrogen (Carlsbad, CA, USA). The Annexin V-FITC Apoptosis Detection Kit I was purchased from Bender Biosciences (San Diego, CA, USA). Microtubule-associated protein 1 light chain 3 (LC3) and rabbit monoclonal antiGAPDH antibodies, and the ECL chemiluminescence western blotting kit were purchased from Santa Cruz Biotechnology, Inc. (Santa Cruz, CA, USA).
Cell culture and viability assay. The MG-63 cells (Shanghai Institute of Cell Biology, Chinese Academy of Sciences Shanghai, China) were maintained in cultured DMEM containing $10 \% \mathrm{FBS}, 100 \mu \mathrm{g} / \mathrm{ml}$ of penicillin and $100 \mu \mathrm{g} / \mathrm{ml}$ of streptomycin at $37^{\circ} \mathrm{C}$ in a $5 \% \mathrm{CO}_{2}$ incubator.

MTT assay. The osteosarcoma MG-63 cells were seeded into a 96-well flat bottom microtiter plates at a density of $1 \times 10^{4}$ cells/ well overnight, and then treated with various concentrations of TanIIA $(0,2.5,5,10$ and $20 \mathrm{mg} / \mathrm{l})$, respectively. To each well a total of $20 \mu \mathrm{l}$ MTT solution $(5 \mathrm{~g} / \mathrm{l})$ was added and the cells were incubated for $4 \mathrm{~h}$. We used an automatic multiwell spectrophotometer to calculate the absorbance value/well at $570 \mathrm{~nm}$. All MTT assays were performed in triplicate. The inhibitory rate for the proliferation of the MG-63 cells was calculated according to the formula: (1 - experimental absorbance value/control absorbance value) $\mathrm{x} 100 \% . \mathrm{IC}_{50}$ values (50\% inhibition concentration) were then calculated using the Statistical Package for the Social Sciences (SPSS, Inc., Chicago, IL, USA).

Detection of apoptosis. Annexin V-FITC/propidium iodide (PI) double staining assay was used to measure apoptosis of the MG-63 cells. After washing the cells with phosphate-buffered saline (PBS) three times, each group of cells was stained following the manufacturer's instructions. The number of apoptotic cells was detected by flow cytometry and analyzed using CellQuest ${ }^{\mathrm{TM}}$ software. Each group was repeatedly measured three times.

Hoechst 33258 staining. The cells were fixed with $3.7 \%$ paraformaldelyde for $30 \mathrm{~min}$ at room temperature, and stained with $10 \mathrm{mg} / \mathrm{l} \mathrm{Hoechst} 33258$ at $37^{\circ} \mathrm{C}$ for $15 \mathrm{~min}$. The MG-63 cells were observed under a fluorescence microscope equipped with a UV filter. Hoechst 33258 freely permeates cell membranes, and apoptotic cells were identified by the presence of condensed or fragmented nuclei that stained bright blue.

Green fluorescent protein (GFP)-LC3 dot assay. The MG-63 cells were transfected with GFP-LC3 plasmids with Lipofectamine 2000 following the manufacturer's instructions. At $24 \mathrm{~h}$ after transfection, the cells were treated with TanIIA for the indicated periods. Leica DM2500 fluorescence microscope was used to analyze the number of LC3-II puncta. The induction of autophagy was quantified by counting the percentage of cells in each group that contained LC3 aggregates.

Western blot analysis. Cells were washed in PBS, and resuspended in RIPA buffer at room temperature. After three freeze/thaw cycles and incubation on ice for $30 \mathrm{~min}$, the lysate was centrifuged at $140,009 \times \mathrm{g}$ for $10 \mathrm{~min}$ at $4^{\circ} \mathrm{C}$. Protein concentration was measured with the Bradford protein assay reagent using bovine serum albumin as a standard. Equal amounts of total protein extracts were separated on $12 \%$ SDS-PAGE gel and transferred to polyvinylidene fluoride (PVDF) membranes. The membranes were blocked in Tris-buffered saline-Tween-20 (TBST) with 5\% non-fat milk for $1 \mathrm{~h}$, and incubated overnight at $4^{\circ} \mathrm{C}$ with the designated 
primary antibodies and with the secondary antibodies for $2 \mathrm{~h}$ at room temperature.

Transmission electron microscopy. The MG-63 cells were fixed overnight at $4^{\circ} \mathrm{C}$ in $2 \%$ paraformaldehyde, $2.5 \%$ glutaraldehyde in $0.1 \mathrm{M}$ sodium cacodylate buffer ( $\mathrm{pH} 7.2$ ), before being postfixed with $1 \% \mathrm{OsO}_{4}$ for $1 \mathrm{~h}$. The cells were then dehydrated in a graded ethanol series and embedded in Agar 100 epoxy resin. Ultrathin sections were mounted on $\mathrm{Cu}$ grids and stained first with uranyl acetate followed by lead citrate.

RNA interference. The cells were transfected with $60 \mathrm{nM}$ of specific or non-targeting siRNA using Lipofectamine 2000 according to the manufacturer's instructions. The cells were treated with indicating doses of TanIIA for the following experiments. The siRNAs were obtained from GenePharma, Ltd. (Shanghai, China). The si-Beclin-1 targeting sequence was: 5'-UUCAACACUCUUCAGCUCAUCAUCC-3'; and the scrambled siRNA sequence was: 5'-UUCUCCGAACGUGUC ACGUTT-3'.

ROS detection. Following TanIIA treatment, the intracellular ROS level was detected by fluorescence microscope using 2',7'-dichlorodihydrofluorescein diacetate (DCFH-DA) 75 staining. Briefly, the MG-63 cells were incubated with $5 \mathrm{mM}$ DCFH-DA for $30 \mathrm{~min}$ in the dark, and washed with serumfree medium three times. The fluorescence was excited at the wavelength of $485 \mathrm{~nm}$ and the corresponding emission wavelength was $520 \mathrm{~nm}$. ROS fluorescence intensity was examined under a Leica DM2500 fluorescence microscope with an analysis software system.

Phase contrast microscopy. The MG-63 cells were seeded at $37^{\circ} \mathrm{C}$ overnight, and then treated with the indicated concentration of TanIIA, respectively. After $48 \mathrm{~h}$, changes in MG-63 cell morphology were dynamically observed under a phase contrast microscope. Autophagy was manifested as cell membrane integrity and cytoplasmic characteristic vacuolation.

Statistical analysis. All data are presented as the mean \pm SD. The differences between the groups were analyzed using the Student's t-test, Statistical analyses were performed using SPSS version 16.0 software (SPSS, Inc., Chicago, IL, USA). $\mathrm{P}<0.05$ was considered to indicate a statistically significant difference.

\section{Results}

TanIIA inhibits MG-63 cell proliferation. As shown in Fig. 1, the MTT assay was used to assess the suppression of the proliferation of MG-63 cells in a dose- and time-dependent manner after treatment with various concentrations of TanIIA $(0,2.5,5,10$ and $20 \mathrm{mg} / \mathrm{l})$ for the indicated time periods. In addition, the half maximal inhibitory concentration value of TanIIA treatment at $48 \mathrm{~h}$ was $8.8 \mathrm{mg} / \mathrm{l}$.

TanIIA induces osteosarcoma MG-63 cell autophagy. In order to determine whether TanIIA induces autophagy, we examined using transmission electron microscopy, the ultrastructure of MG-63 cells treated for $24 \mathrm{~h}$ with or without TanIIA. As

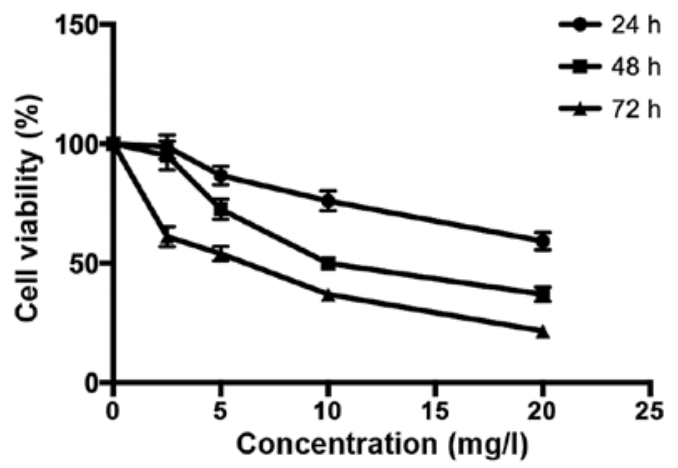

Figure 1. Inhibitory effect of TanIIA on the proliferation of MG-63 cells $(n=3)$.

shown in Fig. 2A-a, the control MG-63 cells showed entire nuclei and endoplasmic reticulum, numerous mitochondria and Golgi. In the TanIIA-treated MG-63 cells (Fig. 2A-b), several clearly visible double-membrane autophagic bodies of different sizes engulfing many cellular organelles, including non-degradable organelles and macromolecules as well as the typical monolayer of autophagosomes could be observed. Swollen mitochondria were noted as well. To further confirm that TanIIA induced autophagy in the MG-63 cells, GFP-LC3 transient green fluorescence transfection was used to assay autophagy induction. When autophagy is at the basic level, GFP-LC3 fluorescence plasmids are dispersed. When autophagy is activated and autophagosomes are increased, GFP-LC3 puncta accumulate. As shown in Fig. 2B and C, compared with the control group which had almost no obvious fluorescent particles, the faintly visible fluorescent granules emerged at a lower dose of $2.5 \mathrm{mg} / 1$ TanIIA. Higher TanIIA concentrations, increased not only the number but also the brightness of the green fluorescent particles.

Studies suggest that the level of LC3II/LC3I is a hallmark of the degree of autophagy. Beclin-1, part of a lipid kinase complex, plays a pivotal role in coordinating the cytoprotective function of autophagy and in opposing the cellular death process of apoptosis (27). In order to further confirm autophagy in the TanIIA-treated MG-63 cells, the expression of LC3II/LC3I and Beclin-1 was analyzed by western blotting; the results of which were similar to those of GFP-LC3 (Fig. 2D and E).

Autophagy is a dynamic process, and when inhibited at the final degradation phase, the LC3II/LC3I level is also elevated. Thus, autophagy flux should be monitored simultaneously. Pharmacological inhibitors and a genetic approach were used. CQ, which blocks autophagosome lysosome fusion and sequestrates autophagosomes (28), was used to inhibit autophagic flux. As shown in Fig. $2 \mathrm{~F}$ and $\mathrm{G}$, following pretreatment with the autophagy inhibitor CQ, the levels of LC3II/LC3I and Beclin-1 were upregulated compared with the TanIIA alone group. We further inhibited autophagy by silencing the Beclin-1 gene, Transfection with si-Beclin-1 resulted in a marked reduction in Beclin-1 and LC3II/LC3I protein expression, while the scrambled siRNA-control group showed no change (Fig. 2H and I). All the above results revealed that Beclin-1-dependent autophagy flux was induced starting from $2.5 \mathrm{mg} / \mathrm{l}$ TanIIA. 

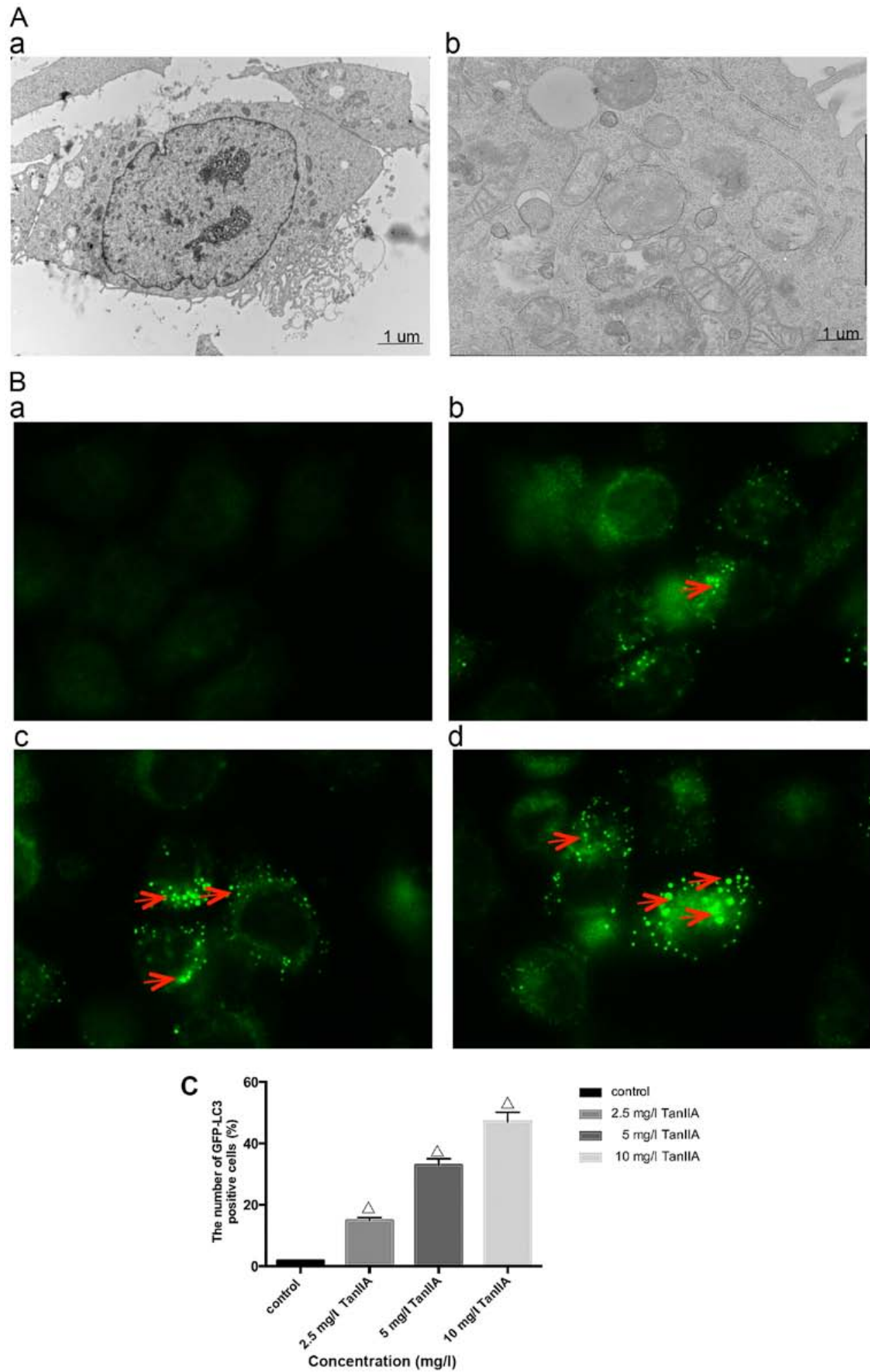

Figure 2. Autophagy is induced by TanIIA in the MG-63 cells. (A) Transmission electron microscopic images of the MG-63 cell line (magnification, x7400). (A-a) Normal morphology of MG-63 cells; (A-b) MG-63 cell autophagy (note the sequestration of the cytoplasmic territory by a double membrane). (B and C) Cells transiently transfected with GFP-LC3 plasmids which were exposed to 0-10 mg/l TanIIA for $48 \mathrm{~h}$. The confocal microscope was used to measure GFP-LC3 fluorescence distribution. The punctate GFP-LC3 is indicative of autophagosomes. (B-a) Control group; (B-b) $2.5 \mathrm{mg} / \mathrm{l} \mathrm{TanIIA} \mathrm{group;}$ (B-c) $5 \mathrm{mg} / \mathrm{l}$ TanIIA group; and (B-d) $10 \mathrm{mg} / 1$ TanIIA group; ${ }^{\wedge} \mathrm{P}<0.05$ vs. the control group.

TanIIA triggers $M G-63$ cell apoptosis. Apoptosis can be induced either by extrinsic stimuli through cell surface death receptors or by intrinsic stimuli through the mitochondrial signaling pathway. The extrinsic pathway is initiated by cell surface death receptor stimulation and activation of caspase-8, while the intrinsic pathway involves cytochrome $c$ release from mitochondria and subsequent caspase-9 activation $(29,30)$. Activation of caspase- 8 and -9 enhances executioner caspase- 3 activation and ultimately upregulation of cleaved-PARP. In order to determine which pathway is 
D

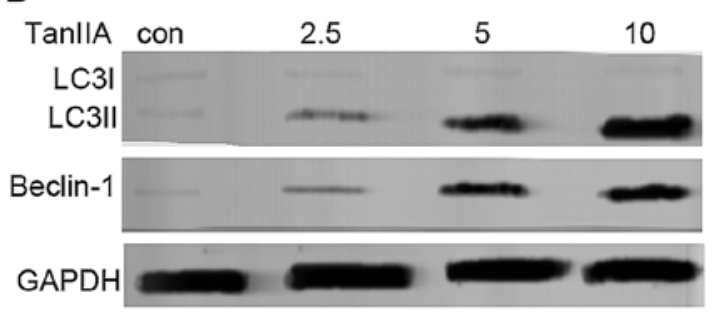

$\mathbf{F}$

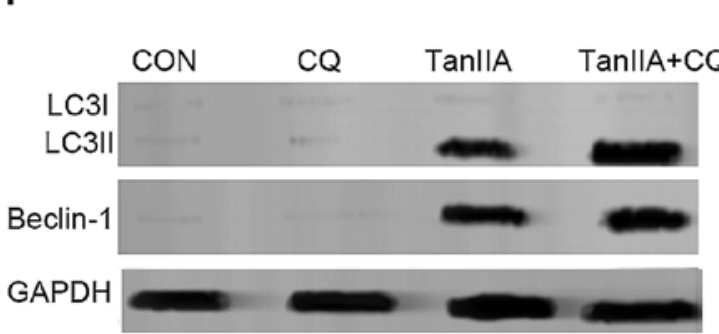

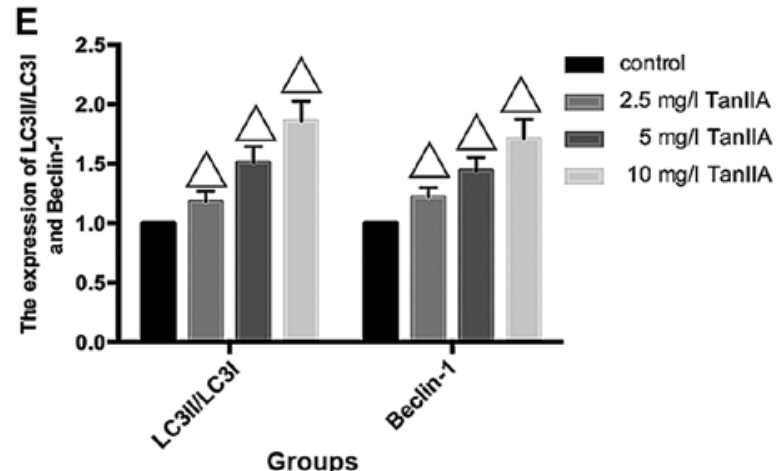

G

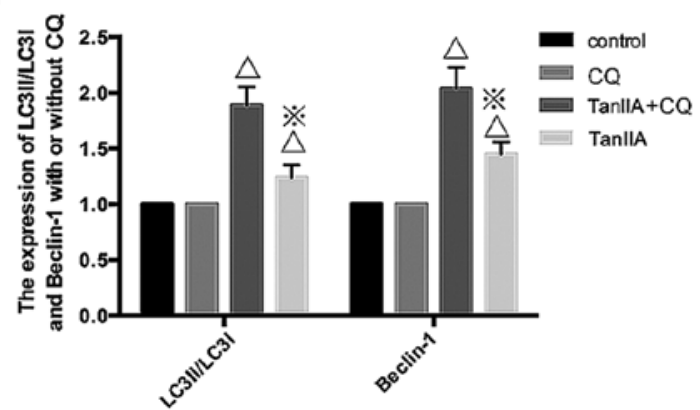

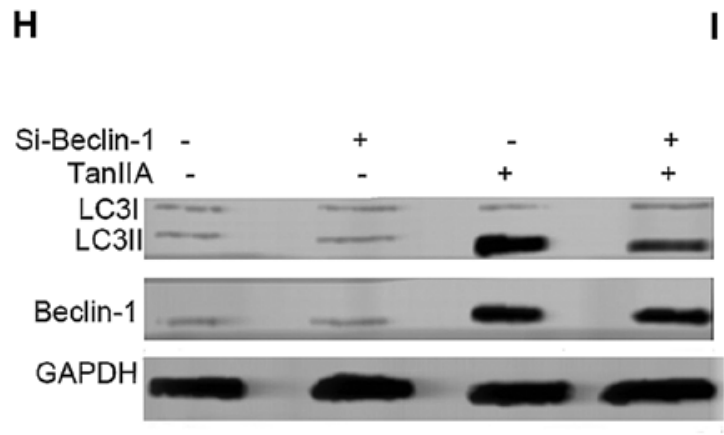

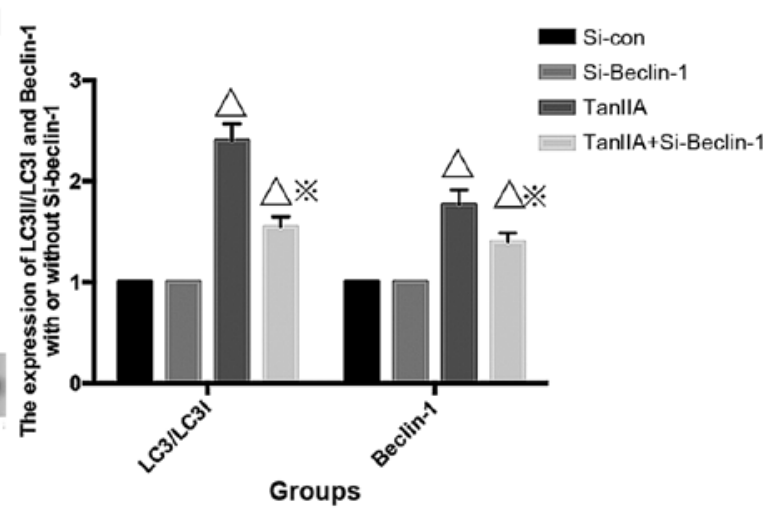

Figure 2. Continued. (D) Western blotting of the protein levels of LC3-II/LC3I and Beclin-1. MG-63 cells were incubated with 0-10 mg/l TanIIA for $48 \mathrm{~h}$ (E) Densitometric analysis of LC3II/LC3I and Beclin-1 expression. GAPDH served as the loading control. All data are expressed as mean \pm SD; ${ }^{\triangle} \mathrm{P}<0.05 \mathrm{vs}$. the control group. (F) Western blotting of the protein levels of LC3-II/LC3I and Beclin-1. MG-63 cells were incubated with TanIIA in the presence or absence of CQ. (G) Densitometric analysis of LC3II/LC3I and Beclin-1 expression. GAPDH served as the loading control. All data are expressed as mean \pm SD; ${ }^{\triangle} \mathrm{P}<0.05$ vs. the control group; ${ }^{\prime} \mathrm{P}<0.05$ vs. the TanIIA alone group. (H) MG-63 cells were transiently transfected with Beclin-1 siRNA and were then treated with TanIIA. The levels of Beclin-1 and LC3II/LC3I were detected by western blot analysis. (I) Densitometric analysis of LC3II/LC3I and Beclin-1 expression. GAPDH served as the loading control. All data are expressed as mean $\pm \mathrm{SD} ;{ }^{\Delta} \mathrm{P}<0.05$ compared with the Si-control group; ${ }^{\circ} \mathrm{P}<0.05$ compared with the Si-control + TanIIA group.

induced by TanIIA in MG-63 cells, caspase- $3,-8$ and -9 as well as cleaved-PARP were assessed by western blotting. As shown in Fig. 3A and B, compared with the control group, neither cleaved-caspase- $3,-8$ and -9 nor cleaved-PARP were detected in the $2.5 \mathrm{mg} / \mathrm{l}$ TanIIA group. However, caspase- $3,-8$ and -9 , and cleaved-PARP were gradually increased in a concentration-dependent (5 and $10 \mathrm{mg} / \mathrm{l}$ TanIIA) manner. To further confirm these findings, caspase inhibitors were employed. The apoptosis rates of the $2.5 \mathrm{mg} / \mathrm{l}$ TanIIA and control groups were not significantly altered, when compared with that of the 5 and $10 \mathrm{mg} / 1$ TanIIA groups pretreated with the caspasespecific inhibitors. As expected (Fig. 3G), we observed a moderate suppressive effect of z-IETD-fmk and z-LEHD-fmk on the TanIIA-induced apoptotic rate while z-VAD-fmk had a more apparent inhibitory effect. All the data implied that TanIIA induced caspase-dependent apoptosis by activating both the extrinsic and intrinsic pathways.

To further clarify whether TanIIA induces apoptosis, flow cytometry and Hoechst 33258 were used. As shown in Fig. 3C and D, compared with the control group, no obvious change in the $2.5 \mathrm{mg} / 1$ TanIIA group was noted, while the apoptotic rates of the other groups were variously increased $(\mathrm{P}<0.05)$. Similar results were found for the Hoechst 33258 experimental results. Normal nuclei emit light blue fluorescence. In case of cell death, markedly induced chromatin condensation or fragmentation, shows bright blue (yellow arrow). DNA fragmentation ratio of the TanIIA-treated cells was predominantly elevated, compared with the 

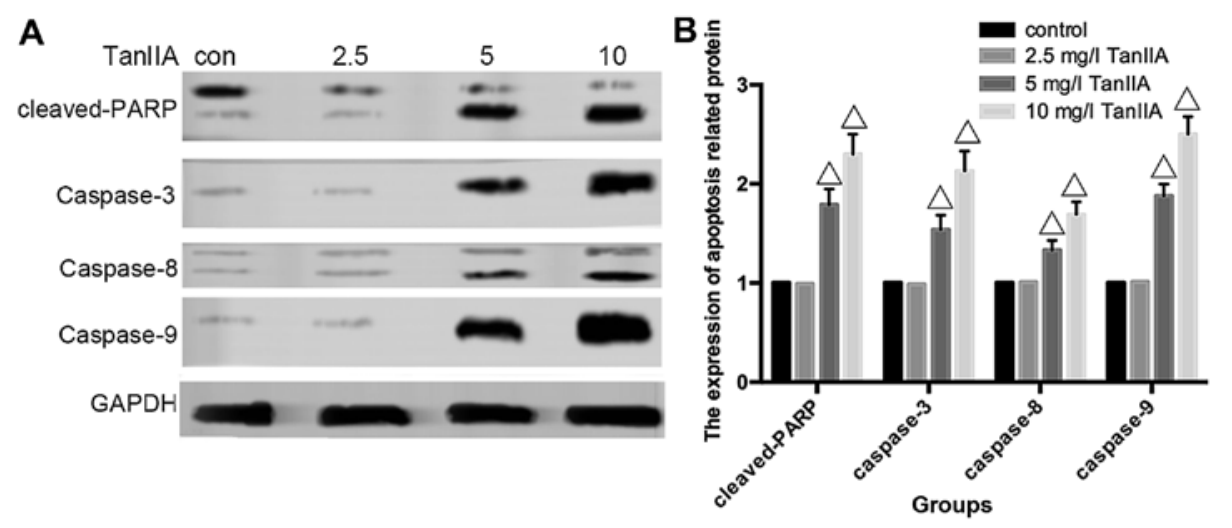

C

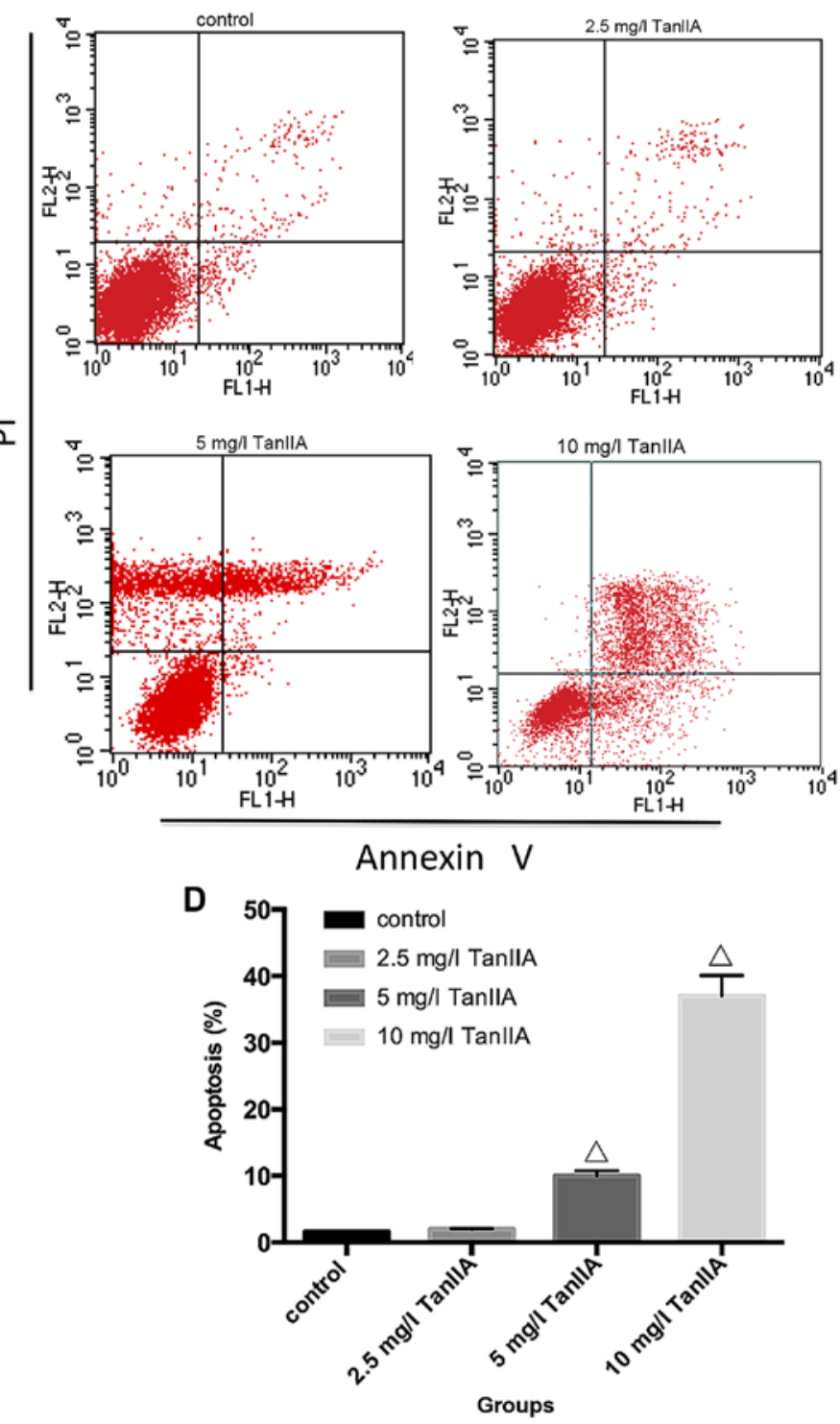

Figure 3. Apoptosis is induced by TanIIA in the MG-63 cells. (A) Western blotting of the protein levels of caspase-3, -8 and -9 and cleaved-PARP, MG-63 cells were incubated with TanIIA. (B) Densitometric analysis of caspase and cleaved-PARP expression. GAPDH served as the loading control. All data are expressed as the mean $\pm \mathrm{SD}$. ${ }^{\triangle} \mathrm{P}<0.05$ vs. the control group. (C) MG-63 cells treated with Tan-IIA were analyzed by flow cytometric analysis. (D) The apoptosis rate is shown in the histogram; ${ }^{\triangle} \mathrm{P}<0.05$ vs. the control group. Data are presented as the mean $\pm \mathrm{SD}$ from three independent experiments.

control and $2.5 \mathrm{mg} / \mathrm{l}$ TanIIA groups, in a dose-dependent manner (Fig. 3E and F).

Inhibition of autophagy induces a double-dose effect on TanIIA-induced apoptosis. Numerous studies have confirmed that antitumor drugs regulate autophagy and apoptosis to exert a therapeutic effect. Our data generally showed that both apoptosis and autophagy were activated in a concentration-dependent manner in the MG- 63 cells following exposure to TanIIA. In our experiments, however, TanIIA 

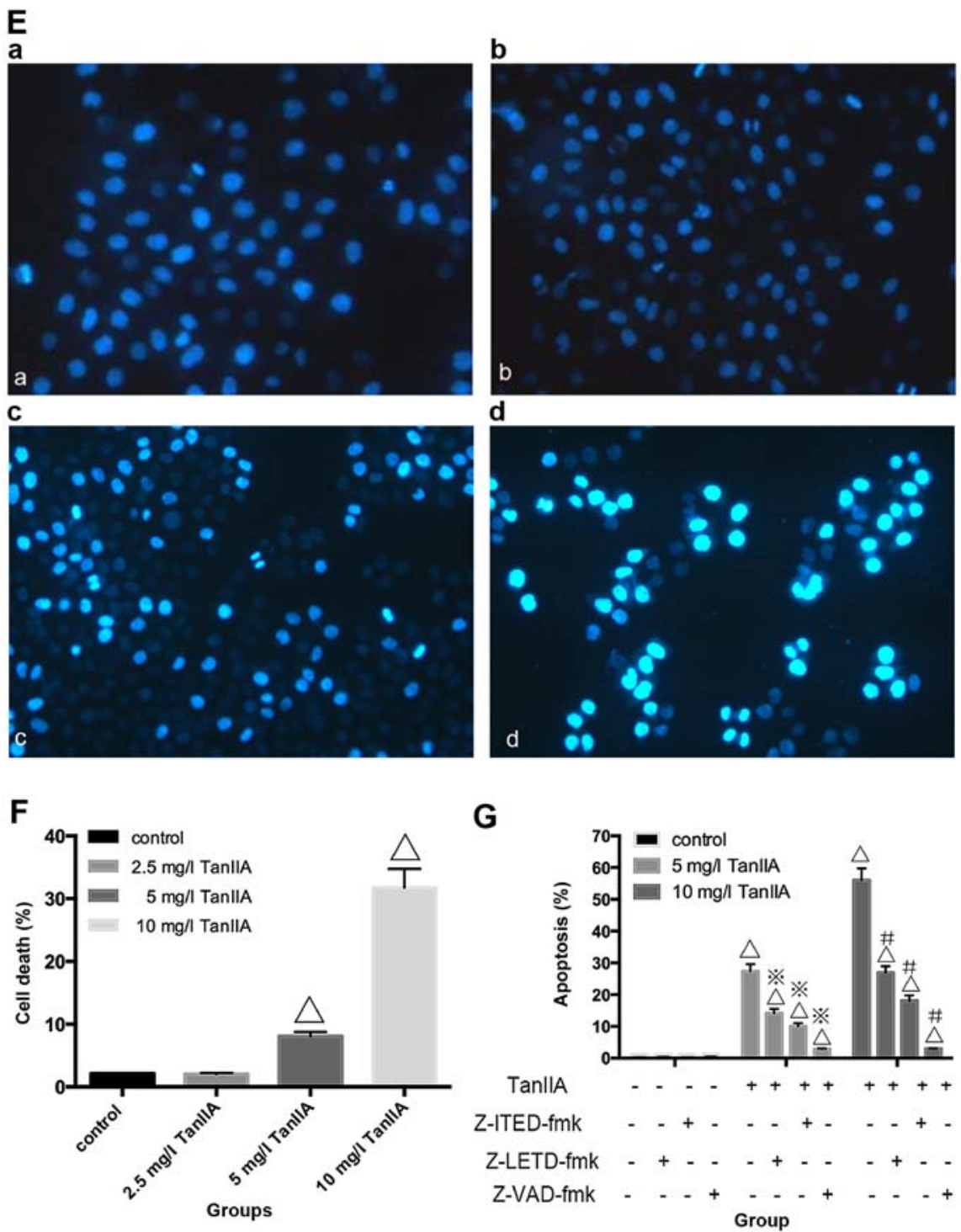

Figure 3. Continued. (E) The cell nuclei were concentrated and were bright blue, or the cell nuclei were lobulated and became debris-like and disposed marginally in the cells treated by TanIIA as observed with Hoechst 33258 fluorescence staining and microscopy. (F) Data from three independent experiments were compared; ${ }^{\triangle} \mathrm{P}<0.05$ vs. the control group. (G) MG-63 cells were incubated with or without TanIIA for $48 \mathrm{~h}$ after a 2-h pretreatment with caspase inhibitors, z-IETD-fmk $(10 \mu \mathrm{M})$, z-LEHD-fmk $(40 \mu \mathrm{M})$ or z-VAD-fmk $(20 \mu \mathrm{M})$. Then, apoptosis was analyzed by flow cytometry; ${ }^{\Delta} \mathrm{P}<0.05$ vs. the control group, "P $<0.05$ vs. the $5 \mathrm{mg} / 1$ TanIIA group, ${ }^{\#} \mathrm{P}<0.05$ vs. the $10 \mathrm{mg} / \mathrm{l}$ TanIIA group.

presented sectional effects; the lower and non-cytotoxic concentration $(2.5 \mathrm{mg} / \mathrm{l})$ showed just autophagy activation and in contrast, no caspase activation nor apoptosis induction was recognized which was in agreement with the MTT assay (Fig. 1). Moreover, following treatment with higher concentrations of TanIIA (5 and $10 \mathrm{mg} / \mathrm{l})$, both apoptosis and autophagy were found to occur in the MG-63 cells.

To further elucidate the role of autophagy in TanIIA-treated MG-63 cells, CQ was employed. As shown in Fig. 4A, the MTT assay indicated that under a condition of low-dose $(2.5 \mathrm{mg} / \mathrm{l})$, TanIIA no obvious change in cell viability was showed in the control, CQ and TanIIA groups, but a slight decreased in the $\mathrm{CQ}+2.5 \mathrm{mg} / 1$ TanIIA group. However, cell viability increased once autophagy was inhibited with CQ + TanIIA groups at high doses (5 and $10 \mathrm{mg} / \mathrm{l}$ ) TanIIA (Fig. 4B and C), that is to say, less apoptotic cells were found in the TanIIA (5 and $10 \mathrm{mg} / \mathrm{l}$ ) and TanIIA + CQ group.
Fig. 4D and E shows that cleaved-PARP, caspase-3 and LC3II/LC3I were modestly increased at $2.5 \mathrm{mg} / 1$ TanIIA + CQ compared with $2.5 \mathrm{mg} / 1$ TanIIA alone. However, decreased cleaved-PARP, cleaved-caspase-3 but LC3II/LC3I was still augmented at a higher dose of TanIIA + CQ compared with a higher dose (5 and $10 \mathrm{mg} / \mathrm{l}$ ) of TanIIA alone (Fig. 4F-I). Based on these observations, it seemed then that MG-63 cells first underwent cytoprotective autophagy and later, due to excessive exposure and cellular damage, protective autophagy was altered to autophagic cell death involved in apoptosis.

In order to confirm this point, we monitored the induction of autophagy and apoptosis over time by performing timecourse analysis. MG-63 cells were treated with $5 \mathrm{mg} / \mathrm{l}$ TanIIA for 0-72 h. Fig. 4J and K shows that LC3II/LC3I accumulated although modestly, starting at $6 \mathrm{~h}$ but became more evident at $12 \mathrm{~h}$. However, caspase- 3 and cleaved-PARP appeared at $24 \mathrm{~h}$, indicated that autophagy preceded apoptosis in the 

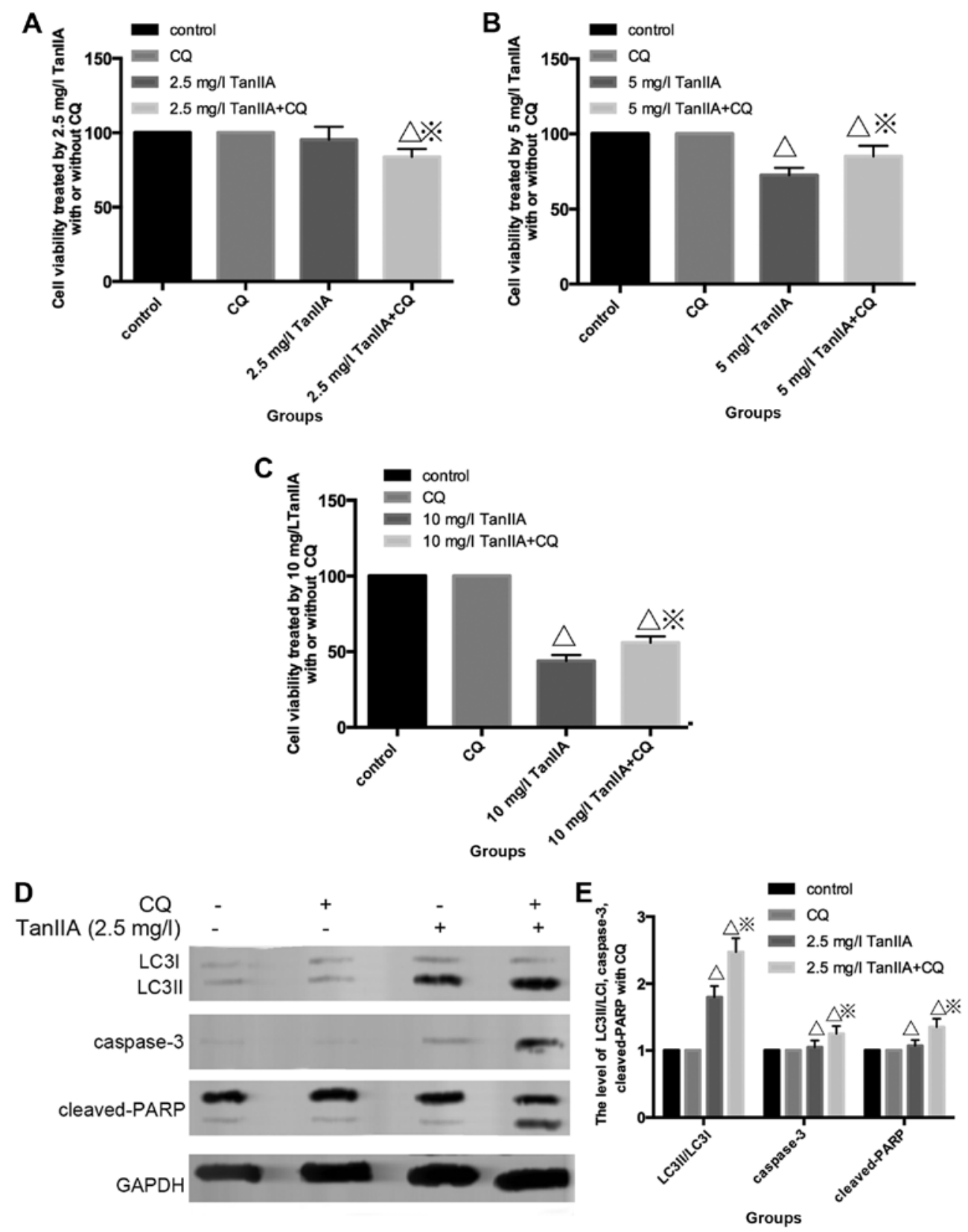

Figure 4. Inhibition of autophagy has a double effect on TanIIA-induced apoptosis. (A and B) Effect of a low-dose (2.5 mg/l) of TanIIA on cell viability as determined by MTT assay with/without pretreatment of $\mathrm{CQ}$. ${ }^{\Delta} \mathrm{P}<0.05$ vs. the control group, $\mathrm{P}<0.05$ vs. the TanIIA group. (B and C) Effects of high-doses (5 and $10 \mathrm{mg} / \mathrm{l}$ ) of TanIIA on cell viability, respectively, as determined by MTT assay with/without pretreatment of CQ. ${ }^{\Delta} \mathrm{P}<0.05$ vs. the control group, ${ }^{\text {"P }}<0.05$ vs. the TanIIA group. (D and E) Apoptosis- and autophagy-related proteins in MG-63 cells following treatment with $2.5 \mathrm{mg} / 1$ TanIIA was explored through western blotting with or without $\mathrm{CQ} .{ }^{\triangle} \mathrm{P}<0.05$ vs. the control group, $" \mathrm{P}<0.05$ vs. the TanIIA group.

TanIIA-treated cells. In addition, following pretreatment with CQ (Fig. 4L and M), LC3II/LC3I was more significantly increased. Moreover, caspase-3 and cleaved-PARP were faintly upregulated at 6 and $12 \mathrm{~h}$, but decreased at $24 \mathrm{~h}$ when compared with the TanIIA alone group. Coincident with the western blot results, the MTT results demonstrated that at $12 \mathrm{~h}$, cell viability was downregulated once autophagy was inhibited. On the contrary, cell viability was increased following pretreatment with CQ at $24 \mathrm{~h}$.

Therefore, we speculated that the TanIIA-treated MG-63 cells presented stage effects: low-dose $2.5 \mathrm{mg} / 1$ TanIIA/shorter time-period induced moderate autophagy to offset a small rate of apoptosis whereby the autophagic pathway could possibly degrade the damaged cellular components, suggesting pro-survival autophagy. In contrast, it is possible that high TanIIA concentrations ( 5 and $10 \mathrm{mg} / \mathrm{l})$ or a longer treatment period induced a significant level of autophagy and damage that was beyond repair, that is to say, a pro-death role of autophagy.

Effect of ROS on TanIIA induces autophagy and apoptosis of MG-63 cells. There is mounting evidence pointing to the involvement of ROS in the upstream of autophagy besides apoptosis (31). We found that the level of ROS was increased in a dose-dependent manner, compared with the control group (Fig. 5A and B); which indicated that TanIIA induced 

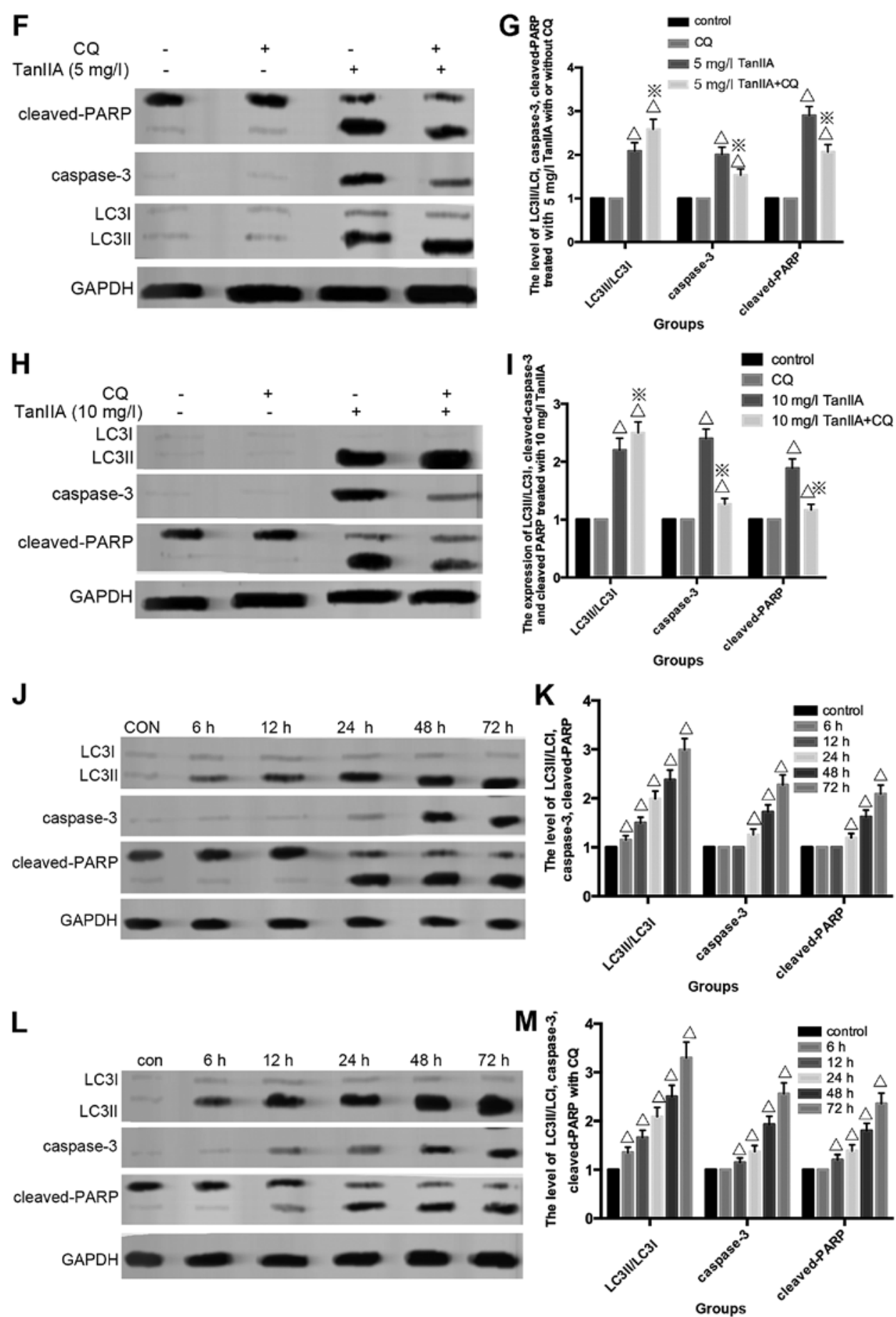

Figure 4. Continued. (F-I) Levels of caspase-3, cleaved-PARP and LC3II/LC3I were assessed in MG-63 cells following treatment with 5 and $10 \mathrm{mg} / \mathrm{l}$ TanIIA by western blotting in the presence or absence of CQ; ${ }^{\circ} \mathrm{P}<0.05$ vs. the control group, "P $<0.05$ vs. the TanIIA group. (J and K) Levels of LC3II/LC3I, caspase-3, cleaved-PARP were assessed in MG-63 cells following treatment with $5 \mathrm{mg} / 1$ TanIIA for $0-72 \mathrm{~h} ;{ }^{\Delta} \mathrm{P}<0.05$ vs. the control group. (L and M) Levels of LC3II/LC3I, caspase-3, cleaved-PARP were assessed in MG-63 cells following treatment with $5 \mathrm{mg} / 1 \mathrm{TanIIA}$ for $0-72 \mathrm{~h}$ with or without CQ; ${ }^{\triangle} \mathrm{P}<0.05 \mathrm{vs}$. the control group.

ROS generation in the MG-63 cells. In order to examine whether TanIIA-induced autophagy and apoptosis was attributed to the generation of ROS in MG-63 cells we examined the effect of NAC, a ROS scavenger on cell viability, cleavedPARP, caspase-3 and LC3II/LC3I. The ROS scavenger NAC almost completely eliminated the ability of TanIIA to induce autophagy and apoptosis, and decreased LC3-II/LC3I, cleaved-caspase-3 and cleaved-PARP levels (Fig. 5C and D) which suggests that the activation of intracellular ROS plays an essential role in TanIIA-induced autophagy.

\section{Discussion}

Tumor occurrence is a multifactorial, multi-stage and complex process, closely related to abnormal regulation of programmed cell death (PCD). Cell apoptosis is one of the classical 

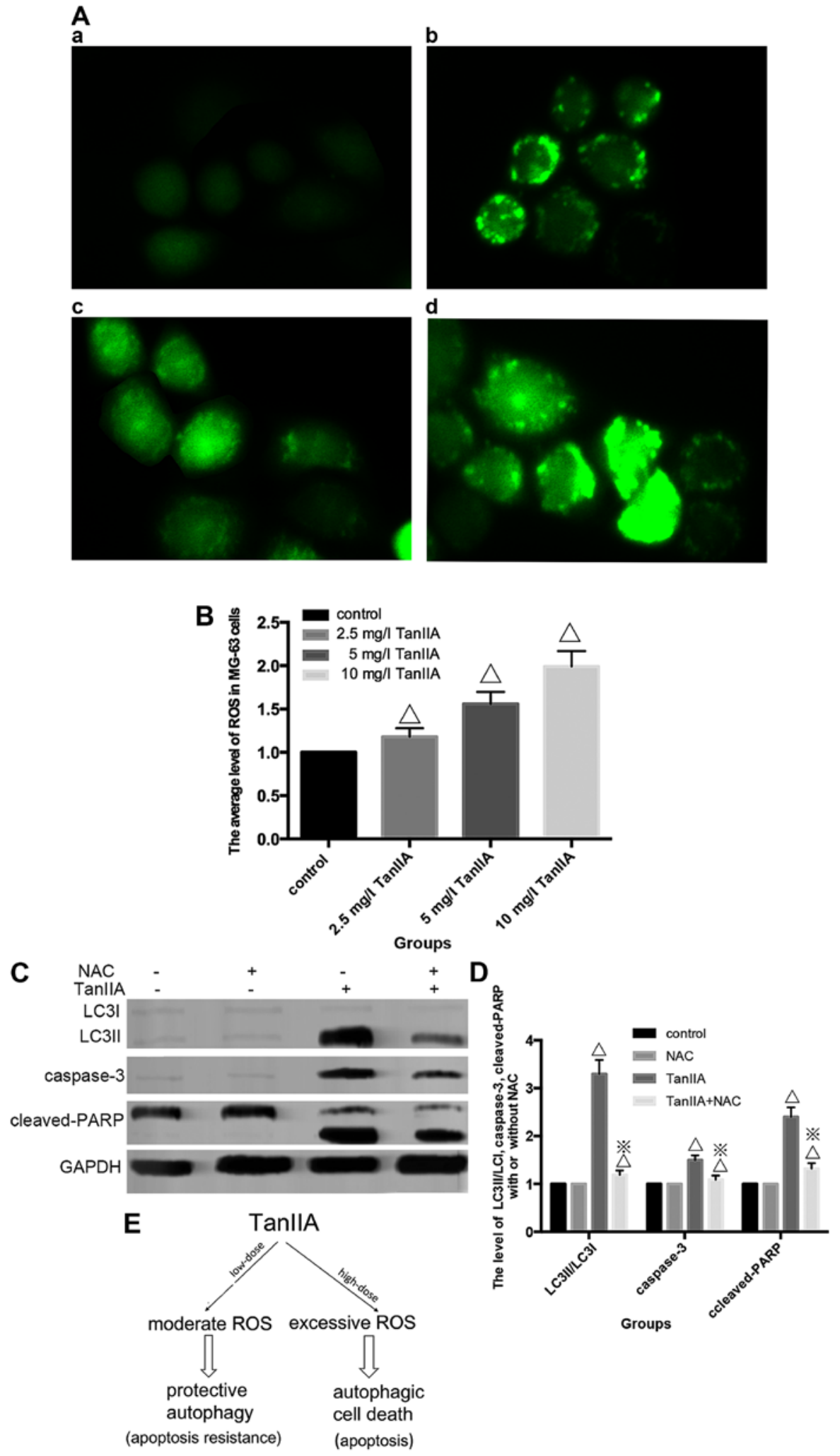

Figure 5. The underlying mechanism involved in the activation of autophagy and apoptosis by TanIIA in MG-63 cells. (A) The average fluorescence intensity of ROS which was induced by TanIIA in the MG-63 cells. (A-a) Control group; (A-b) $2.5 \mathrm{mg} / 1$ TanIIA; (A-c) $5 \mathrm{mg} / 1 \mathrm{TanIIA}$; (A-d) $10 \mathrm{mg} / 1$ TanIIA (B) The mean levels are shown in the histogram. Data are presented as the mean $\pm \mathrm{SD}$ from three independent experiments; ${ }^{\triangle} \mathrm{P}<0.05$ vs. the control group. (C) Western blotting of the protein levels of LC3II/LC3I, cleaved-PARP and caspase-3. MG-63 cells were incubated with TanIIA in the presence or absence of NAC. (D) Densitometric analysis of LC3II/LC3I, cleaved-PARP and caspase-3 expression. GAPDH served as the loading control. All data are expressed as mean \pm SD; ${ }^{\triangle} \mathrm{P}<0.05$ vs. the control group, $" \mathrm{P}<0.05$ vs. the TanIIA group. (E) Hypothetic model illustrating the differential effects of TanIIA on MG-63 cells.

mechanisms of PCD and has been extensively researched as the main strategy in the treatment of cancer. The relationship of autophagy and apoptosis is a research 'hotspot'. The use of autophagy to control tumor development and the corresponding treatment intervention strategy, is one of the means to study the prevention and control cancer. 
In our study, we found that when compared with the control group, the cell viability of MG-63 cells incubated with $2.5 \mathrm{mg} / \mathrm{l}$ TanIIA was not statistically significantly altered. However, at the range of 2.5-20 mg/l TanIIA, osteosarcoma MG-63 cell proliferation was inhibited in dose- and timedependent manner.

Similar to Gao et al (23), we also observed characteristic autophagosomes which embraced extra-large proteins and organelles under transmission electron microscope. The autophagy-related protein LC3II/LC3I and Beclin-1 expression were upregulated and GFP-LC3 green fluorescence plasmids accumulated starting from $2.5 \mathrm{mg} / 1$ TanIIA. In addition, following pretreatment with CQ and Si-Beclin-1, the level of LC3II/LC3I as well as Beclin-1 was altered. All the above experiments confirmed that TanIIA triggered Beclin-1-dependent autophagy in the osteosarcoma MG-63 cells.

In line with Zhang etal(26), we revealed that TanIIA induced apoptosis by activating both extrinsic and intrinsic pathways. However, at the dose of $2.5 \mathrm{mg} / 1$ TanIIA, caspase-3, -8 and -9 , and cleaved-PARP, had no appreciable upregulation. When the TanIIA dose was increased to 5 and $10 \mathrm{mg} / 1$, evidence of apoptosis was confirmed by flow cytometry and Hoechst 33258. In addition, following pretreatment with the caspase inhibitors, the apoptotic rate was decreased to varying degrees.

The role of TanIIA-induced autophagy in cancer treatment, has been debated: Gao et al (23) and Li et al (24) found that TanIIA-induced autophagy failed to benefit cytotoxicity in their experiments. However, Yun et al (25) reported that TanIIA-induced autophagic cell death benefited cancer treatment in leukemic cells. The role of autophagy was positive or negative for tumor growth or tumor therapy, according to the developmental stage of the tumor as well as the tissue or cells targeted. In recent years, autophagy has been recognized as another target for tumor therapy in addition to apoptosis. The relationship between autophagy and apoptosis is regarded as the key to the survival of cells.

Several studies have demonstrated that both apoptosis and autophagy occur concomitantly in the same cells under certain circumstances. In our experiment, autophagy also played a double role. Following treatment with $2.5 \mathrm{mg} / 1$ TanIIA, increased LC3II/LC3I verified generation of autophagy, but there was no evidence of apoptosis generation. In addition, for high-doses of TanIIA ( 5 and $10 \mathrm{mg} / \mathrm{l}$ ), not only $5 \mathrm{mg} / \mathrm{l}$ TanIIA, but also $10 \mathrm{mg} / 1$ TanIIA, LC3II/LC3I was significantly upregulated and statistical significance of apoptosis induction was observed. Al Dhaheri et al (32) found that lower and non-cytotoxic doses of carnosol induced ( $25 \mathrm{mM})$ autophagy alone, which was the same as a low-dose of tetrandrine (33) in human hepatocellular carcinoma. Nonetheless, pretreatment with autophagy inhibitor CQ, and a low-dose $2.5 \mathrm{mg} / 1$ TanIIA, increased LC3II/LC3I, caspase-3 and cleaved-PARP, and the cell viability was slightly lower than the $2.5 \mathrm{mg} / 1$ TanIIA alone group. The results of 5 and $10 \mathrm{mg} / 1$ TanIIA treatment were contrary to $2.5 \mathrm{mg} / \mathrm{l}$ TanIIA. Decreased apoptosis was noted and cell viability increased. Moreover, we used $5 \mathrm{mg} / 1$ TanIIA to treat the MG-63 cells for 0-72 h. LC3II/LC3I was slightly higher at $6 \mathrm{~h}$, significantly increased at $12 \mathrm{~h}$, and apoptosis occurred at $24 \mathrm{~h}$. In addition, pre-incubation with CQ regulated the expression of caspase-3, and cleaved-PARP was regulated at 6 and $12 \mathrm{~h}$, and decreased at $24 \mathrm{~h}$.
The above experimental results unveiled that regardless of the TanIIA dose or treatment period, autophagy occurred earlier than apoptosis. In addition, Shrivastava et al (34) concluded that the ratio of cannabidiol-induced autophagy and apoptosis changed at various times. Strikingly, following pretreatment with CQ, apoptotic cells appeared at $2.5 \mathrm{mg} / 1$ TanIIA and at shorter treatment periods; and for both high-dose TanIIA or a longer treatment time, the apoptotic rate decreased. This showed that for low-dose and shorter treatment time, moderate autophagy played a pro-survival role against little apoptosis in the MG-63 cells. Excessive autophagy caused by higher doses and longer treatment time, participated in or contributed to cell death, thus played a pro-death role.

Evidence suggests that many antitumor drugs emphasize the pivotal role of ROS production in inducing autophagy and cell death in cancer therapy $(35,36)$. Similarly, in the present study, we observed that TanIIA enhanced ROS generation in the MG-63 cells in a dose- and time-dependent manner. Recent studies have shown that the extent of ROS levels produced in response to anticancer agents elicited different effects on the cancer cells. While low level ROS generation was shown to induce autophagy, excessive ROS accumulation triggered both apoptosis and cell death (37). In agreement with these studies, we found that, depending (Fig. 5E) on the working-dose and exposure periods, TanIIA elicited different responses in the MG-63 cells. We found that low-dose TanIIA $(2.5 \mathrm{mg} / \mathrm{l})$ as well as shorter treatment periods resulted in a basic level of ROS production and autophagy. We believe that in this limited range, autophagy was induced to remove damaged organelles as a self-defense survival mechanism.

A prolonged exposure as well as higher concentrations of TanIIA (5 and $10 \mathrm{mg} / \mathrm{l}$ ) led to excessive ROS production, which ultimately resulted in higher levels of oxidative damage that exceeded the cell repair capabilities that eventually caused autophagic cell death and caspase-dependent apoptosis. These findings which highlighted the key role of ROS accumulation are supported by the following evidence: the abrogation of ROS production by NAC, and a total decrease in autophagy and apoptosis. Altogether, these data strongly demonstrated that ROS production in response to TanIIA acted as an upstream effector for autophagy and subsequent apoptosis induction. Similar mechanism has been described by some reports, for example: Lin et al for safingol (38), an anticancer drug in phase I clinical trial, which has been shown to mediate a concentration-dependent effect on MDA-MB-231 and HT29 cancer cells (38). These authors showed that a low concentration of safingol triggered autophagy as a damage repair mechanism, while a higher concentration led to cell death. Al Dhaheri et al (32) found that low-dose carnosol induced moderate ROS and led to protective autophagy, while high expression of ROS generated PCD.

In this experiment, we found for the first time a sequential effect of TanIIA on osteosarcoma MG-63 cells. Its basic function is the degree of oxidative stress, different from other studies concerning TanIIA treatment (23-25). However, there is no doubt that the underlying mechanisms of TanIIA in osteosarcoma therapy requires further investigation; for example, to ascertain whether DNA damage participates in TanIIAtreated MG-63 cells. In addition, endoplasmic reticulum (ER) stress is an important mechanism involved in the activation of 
autophagy and apoptosis, and elucidation of the relationship between ER stress and ROS requires investigation. In addition, the ERK signaling pathway is closely associated with ER stress-mediated autophagy, which was not investigated in the present study. Thus, further exploration is needed to identify the interplay between them.

In conclusion, our study provides experimental evidence that ROS play a pivotal role in mediating the cytotoxic effect of TanIIA on MG-63 cells. Together, these data suggest that TanIIA may be a potential agent with which to treat osteosarcoma at appropriate concentrations. When combined with ROS-generating agonists, a synergistic effect is exhibited by executing different modes of cell death.

\section{References}

1. Ottaviani $\mathrm{G}$ and Jaffe N: The epidemiology of osteosarcoma Cancer Treat Res 152: 3-13, 2009.

2. PosthumaDeBoer J, Witlox MA, Kaspers GJ and van Royen BJ: Molecular alterations as target for therapy in metastatic osteosarcoma: A review of literature. Clin Exp Metastasis 28: 493-503, 2011.

3. Edinger AL and Thompson CB: Death by design: Apoptosis, necrosis and autophagy. Curr Opin Cell Biol 16: 663-669, 2004.

4. Yorimitsu T and Klionsky DJ: Autophagy: Molecular machinery for self-eating. Cell Death Differ 12 (Suppl 2): S1542-S1552, 2005.

5. Hale AN, Ledbetter DJ, Gawriluk TR and Rucker EB III: Autophagy: Regulation and role in development. Autophagy 9: 951-972, 2013

6. Apel A, Zentgraf H, Büchler MW and Herr I: Autophagy - A double-edged sword in oncology. Int J Cancer 125: 991-995, 2009.

7. Oral O, Akkoc Y, Bayraktar O and Gozuacik D: Physiological and pathological significance of the molecular cross-talk between autophagy and apoptosis. Histol Histopathol 31: 479-498, 2016.

8. D'Autreaux B and Toledano MB: ROS as signaling molecules: Mechanisms that generate specificity in ROS homeostasis. Nat Rev Mol Cell Biol 8: 813-824, 2007.

9. Gough DR and Cotter TG: Hydrogen peroxide: a Jekyll and Hyde signalling molecule. Cell Death Dis 2: e213, 2011.

10. Cross CE, Halliwell B, Borish ET, Pryor WA, Ames BN, Saul RL, McCord JM and Harman D: Oxygen radicals and human disease. Ann Intern Med 107: 526-545, 1987.

11. Fu J, Huang H, Liu J, Pi R, Chen J and Liu P: Tanshinone IIA protects cardiac myocytes against oxidative stress-triggered damage and apoptosis. Eur J Pharmacol 568: 213-221, 2007.

12. Li X, Xu X, Wang J, Yu H, Wang X, Yang H, Xu H, Tang S, Li Y, Yang L, et al: A system-level investigation into the mechanisms of Chinese Traditional Medicine: Compound Danshen Formula for cardiovascular disease treatment. PLoS One 7: e43918, 2012

13. Li YI, Elmer G and Leboeuf RC: Tanshinone IIA reduces macrophage death induced by hydrogen peroxide by upregulating glutathione peroxidase. Life Sci 83: 557-562, 2008.

14. Wang X, Wei Y, Yuan S, Liu G, Lu Y, Zhang J and Wang W: Potential anticancer activity of tanshinone IIA against human breast cancer. Int J Cancer 116: 799-807, 2005.

15. Liu F, Yu G, Wang G, Liu H, Wu X, Wang Q, Liu M, Liao K, Wu M, Cheng X, et al: An NQO1-initiated and p53-independent apoptotic pathway determines the anti-tumor effect of tanshinone IIA against non-small cell lung cancer. PLoS One 7: e42138, 2012.

16. Xu D, Lin TH, Zhang C, Tsai YC, Li S, Zhang J, Yin M, Yeh S and Chang C: The selective inhibitory effect of a synthetic tanshinone derivative on prostate cancer cells. Prostate 72: 803-816, 2012.

17. Chiu SC, Huang SY, Chang SF, Chen SP, Chen CC, Lin TH, Liu HH, Tsai TH, Lee SS, Pang CY, et al: Potential therapeutic roles of tanshinone IIA in human bladder cancer cells. Int J Mol Sci 15: 15622-15637, 2014

18. Fu P, Du F, Chen W, Yao M, Lv K and Liu Y: Tanshinone IIA blocks epithelial-mesenchymal transition through HIF-1 $\alpha$ downregulation, reversing hypoxia-induced chemotherapy resistance in breast cancer cell lines. Oncol Rep 31: 2561-2568, 2014.
19. Lin C, Wang L, Wang H, Yang L, Guo H and Wang X: Tanshinone IIA inhibits breast cancer stem cells growth in vitro and in vivo through attenuation of IL-6/STAT3/NF- $\mathrm{KB}$ signaling pathways. J Cell Biochem 114: 2061-2070, 2013.

20. Chen J, Shi DY, Liu SL and Zhong L: Tanshinone IIA induces growth inhibition and apoptosis in gastric cancer in vitro and in vivo: Oncol Rep 27: 523-528, 2012.

21. Wang L, Zhang C, Guo Y, Su ZY, Yang Y, Shu L and Kong AN: Blocking of JB6 cell transformation by tanshinone IIA: Epigenetic reactivation of Nrf2 antioxidative stress pathway. AAPS J 16: 1214-1225, 2014.

22. Li FQ, Zeng DK, Jia CL, Zhou P, Yin L, Zhang B, Liu F and Zhu Q: The effects of sodium tanshinone IIa sulfonate pretreatment on high glucose-induced expression of fractalkine and apoptosis in human umbilical vein endothelial cells. Int J Clin Exp Med 8: 5279-5286, 2015.

23. Gao H, Sun W, Zhao W, Hao W, Leung CH, Lu J and Chen X: Total tanshinones-induced apoptosis and autophagy via reactive oxygen species in lung cancer 95D cells. Am J Chin Med 43: $1265-1279,2015$.

24. Li CL, Han XC, Zhang H, Wu J and Li B: The interplay between autophagy and apoptosis induced by tanshinone IIA in prostate cancer cells. Tumour Biol 37: 7667-7674, 2016.

25. Yun SM, Jung JH, Jeong SJ, Sohn EJ, Kim B and Kim SH: Tanshinone IIA induces autophagic cell death via activation of AMPK and ERK and inhibition of mTOR and p70 S6K in KBM-5 leukemia cells. Phytother Res 28: 458-464, 2014.

26. Zhang Y, Wei RX, Zhu XB, Cai L, Jin W and $\mathrm{Hu} \mathrm{H}$ : Tanshinone IIA induces apoptosis and inhibits the proliferation, migration, and invasion of the osteosarcoma MG-63 cell line in vitro. Anticancer Drugs 23: 212-219, 2012.

27. Cao Y and Klionsky DJ: Physiological functions of Atg6/Beclin 1: A unique autophagy-related protein. Cell Res 17: 839-849, 2007.

28. Carew JS, Medina EC, Esquivel JA II, Mahalingam D, Swords R, Kelly K, Zhang H, Huang P, Mita AC, Mita MM, et al: Autophagy inhibition enhances vorinostat-induced apoptosis via ubiquitinated protein accumulation. J Cell Mol Med 14: 2448-2459, 2010.

29. Fulda S and Debatin KM: Extrinsic versus intrinsic apoptosis pathways in anticancer chemotherapy. Oncogenne 25: 4798-4811, 2006.

30. Tait SW and Green DR: Mitochondrial regulation of cell death. Cold Spring Harb Perspect Biol 5: a008706, 2013.

31. Kongara S and Karantza V: The interplay between autophagy and ROS in tumorigenesis. Front Oncol 2: 171, 2012.

32. Al Dhaheri Y, Attoub S, Ramadan G, Arafat K, Bajbouj K, Karuvantevida N, AbuQamar S, Eid A and Iratni R: Carnosol induces ROS-mediated beclin1-independent autophagy and apoptosis in triple negative breast cancer. PLoS One 9: e109630, 2014.

33. Gong K, Chen C, Zhan Y, Chen Y, Huang Z and Li W: Autophagy-related gene 7 (ATG7) and reactive oxygen species/extracellular signal-regulated kinase regulate tetrandrine-induced autophagy in human hepatocellular carcinoma. J Biol Chem 287: 35576-35588, 2012.

34. Shrivastava A, Kuzontkoski PM, Groopman JE and Prasad A: Cannabidiol induces programmed cell death in breast cancer cells by coordinating the cross-talk between apoptosis and autophagy. Mol Cancer Ther 10: 1161-1172, 2011.

35. Dewaele M, Maes H and Agostinis P: ROS-mediated mechanisms of autophagy stimulation and their relevance in cancer therapy. Autophagy 6: 838-854, 2010.

36. Panda PK, Mukhopadhyay S, Das DN, Sinha N, Naik PP and Bhutia SK: Mechanism of autophagic regulation in carcinogenesis and cancer therapeutics. Semin Cell Dev Biol 39: 43-55, 2015.

37. Chen $\mathrm{N}$ and Karantza-Wadsworth V: Role and regulation of autophagy in cancer. Biochem Biophys Acta 1793: 1516-1523, 2009.

38. Ling LU, Tan KB, Lin $\mathrm{H}$ and Chiu GN: The role of reactive oxygen species and autophagy in safingol-induced cell death. Cell Death Dis 2: e129, 2011. 